\title{
BMJ Open Effects of retinopathy and chronic kidney disease on long-term mortality in type 2 diabetic inpatients with normal urinary albumin or protein: a retrospective cohort study
}

Yu-Hsuan Li, ${ }^{1}$ Wayne H-H Sheu, ${ }^{1,2}$ I-Te Lee ${ }^{1,2,3}$

To cite: Li Y-H, Sheu WH-H, Lee I-T. Effects of retinopathy and chronic kidney disease on long-term mortality in type 2 diabetic inpatients with normal urinary albumin or protein: a retrospective cohort study. BMJ Open 2018;8:e021655. doi:10.1136/ bmjopen-2018-021655

- Prepublication history and additional material for this paper are available online. To view these files, please visit the journal online (http://dx.doi org/10.1136/bmjopen-2018021655).

Received 13 January 2018 Revised 6 June 2018 Accepted 12 June 2018

Check for updates

(c) Author(s) (or their employer(s)) 2018. Re-use permitted under CC BY-NC. No commercial re-use. See rights and permissions. Published by BMJ.

${ }^{1}$ Division of Endocrinology and Metabolism, Department of Internal Medicine, Taichung Veterans General Hospital, Taichung, Taiwan

${ }^{2}$ School of Medicine, National Yang-Ming University, Taipei, Taiwan

${ }^{3}$ School of Medicine, Chung Shan Medical University, Taichung, Taiwan

Correspondence to Dr I-Te Lee; itlee@vghtc.gov.tw

\section{ABSTRACT}

Objective Normoalbuminuric chronic kidney disease (NA-CKD) is recognised as a distinct phenotype of diabetic kidney disease, but the role of diabetic retinopathy (DR) in predicting long-term mortality among these patients remains unclear. Here, we aimed to investigate the effects of $D R$ and CKD on mortality in type 2 diabetic patients with normoalbuminuria.

Design We conducted this study as a retrospective cohort study.

Setting We collected clinical information from the medical records of a public medical centre in central Taiwan.

Participants Patients with type 2 diabetes $(n=665)$ who were hospitalised due to poor glucose control were consecutively enrolled and followed for a median of 6.7 years (IQR 4.1-9.6 years). Patients with either urinary protein excretion $>150 \mathrm{mg} /$ day or urine albumin excretion $>30 \mathrm{mg} /$ day were excluded.

Primary outcome measure All-cause mortality served as the primary follow-up outcome, and the mortality data were obtained from the national registry in Taiwan. Results The patients with CKD and DR showed the highest mortality rate $(\log -$ rank $p<0.001)$. The risks of all-cause mortality (HR 2.263; 95\% Cl 1.551 to 3.302) and cardiovascular mortality (HR 2.471; $95 \% \mathrm{Cl} 1.421$ to 4.297) were significantly greater in patients with CKD and DR than in those without CKD or DR, after adjusting for the associated risk factors.

Conclusions DR is an independent predictor for all-cause and cardiovascular mortality in type 2 diabetic inpatients with normoalbuminuria. Moreover, DR with CKD shows the highest risks of all-cause and cardiovascular mortality among these patients. Funduscopy screening can provide additive information on mortality in patients with type 2 diabetes, even among those with NA-CKD.

\section{INTRODUCTION}

Diabetes is associated with microvascular complications and is the leading cause of both end-stage renal disease and blindness. ${ }^{1-5}$ Diabetic kidney disease (DKD) is a complex and heterogeneous disease, particularly among patients with type 2 diabetes. ${ }^{6}$

\section{Strengths and limitations of this study}

- Twenty-four-hour urine collection during the hospitalisation period.

- A median follow-up period of 6.7 years.

- Mortality data obtained from a National Health Insurance registry with a nationwide coverage rate of over $99 \%$ in Taiwan.

- In addition to normoalbuminuria, normoproteinuria was also included in the analyses due to limited case numbers.

The urinary albumin level is an important biomarker for $\mathrm{DKD}^{7}$ and is predictive of all-cause and cardiovascular mortality. ${ }^{6} 8$ Extensive resources and efforts have focused on understanding and preventing albuminuria, and its prevalence has consequently been significantly reduced; however, the prevalence of low estimated glomerular filtration rate (eGFR) has still increased among patients with diabetes. ${ }^{9}$

Normoalbuminuria was reported in $36 \%$ of type 2 diabetic patients with chronic kidney disease (CKD) in the Third National Health and Nutrition Examination Survey (NHANES) 1988-1994, ${ }^{10}$ and was reported in $48.1 \%$ of diabetic patients with CKD in the NHANES 2005-2008. ${ }^{9}$ The prevalence of normoalbuminuria in CKD appears to have increased over the last 15 years. ${ }^{9}$ With the recent progress in the management of diabetic complications, it appears that this paradigm has shifted, and the phenotype of normoalbuminuric chronic kidney disease (NA-CKD) has emerged. ${ }^{611}$ Hence, the mechanism by which NA-CKD leads to cardiovascular disease and mortality remains a popular area of research.

Diabetic retinopathy (DR) has been traditionally recognised as an early 
reflection of general microangiopathy in patients with type 2 diabetes. ${ }^{3} 1213$ Accumulating evidence has shown that DR is a predictor of cardiovascular disease and all-cause mortality in subjects with type 2 diabetes. ${ }^{14-17}$ However, some studies have reported that DR is not predictive of mortality in the presence of DKD, ${ }^{18} 19$ and the association between DR and cardiovascular disease becomes non-significant after adjusting for the albuminuria. ${ }^{20-22}$

In the present study, we aimed to investigate the mortality risk among type 2 diabetic patients without albuminuria, and we hypothesised that DR was predictive of long-term mortality in type 2 diabetic patients with NA-CKD or without NA-CKD.

\section{METHODS}

\section{Setting and participants}

This retrospective cohort study was conducted at Taichung Veterans General Hospital. Clinical data were obtained by reviewing the medical records of diabetic patients hospitalised between August 1996 and August 2007. The inclusion criteria were (1) adult diabetic inpatients based on the clinical diagnosis, (2) admission to the Endocrinology and Metabolism section due to a primary diagnosis of poor glucose control, (3) availability of eGFR data and (4) performance of 24-hour urine collection for the determination of albumin or protein levels during the hospitalisation period. The exclusion criteria included (1) urinary protein excretion $\geq 150 \mathrm{mg} /$ day or urine albumin excretion $\geq 30 \mathrm{mg} / \mathrm{day},{ }^{23}$ (2) death during this hospitalisation period, (3) systolic blood pressure $<90 \mathrm{~mm} \mathrm{Hg}$, (4) urine volume $<300 \mathrm{~mL} /$ day, (5) diagnosis of diabetes other than type 2 and (6) the unavailability of reports documenting eye fundal examinations for retinopathy by an ophthalmologist during the hospitalisation period. In repeatedly hospitalised patients, data recorded from the last admission during the study period were used.

\section{Patient and public involvement}

All-cause mortality served as the primary outcome in this retrospective cohort study, and the mortality data were obtained from the national registry in Taiwan. We collected clinical information from the medical records at Taichung Veterans General Hospital. The Institutional Review Board waived the need for informed consent before reviewing the medical records.

\section{Variables}

A normal urinary albumin level was defined as 24-hour urine albumin excretion $<30 \mathrm{mg} .{ }^{23-25}$ In those inpatients with only protein detected, however, normal urine protein was defined as 24-hour urine protein $<150 \mathrm{mg} .{ }^{23}$ CKD was defined as an eGFR $<60 \mathrm{~mL} / \mathrm{min} / 1.73 \mathrm{~m}^{2}$. The eGFR was calculated by the Modification of Diet in Renal Disease (MDRD) equation: $186 \times($ serum creatinine $(\mathrm{mg} /$ $\mathrm{dL}))^{-1.154} \times(\text { age }(\text { year }))^{-0.203}(\times 0.742$, if female $) \mathrm{mL} /$ $\min / 1.73 \mathrm{~m}^{2}{ }^{24}$
DR includes non-proliferative DR and proliferative DR. ${ }^{26}$ DR was screened using funduscopic examinations by ophthalmologists based on formal consultations. Retinal angiography (CF-60UVi fundus camera; Canon, Japan) was subsequently arranged for the confirmation of retinopathy diagnosis in cases with abnormal funduscopic findings. Hypertension was defined as blood pressure higher than $130 / 80 \mathrm{~mm} \mathrm{Hg}$ or a history of antihypertensive medication use. After medical information was collected from our hospital, we also obtained the mortality data up to December 2011 from the Collaboration Centre of Health Information Application, Department of Health, Executive Yuan, Taiwan. The causes of death were categorised according to the International Classification of Disease (ICD), Ninth Revision, Clinical Modification diagnostic criteria before 2008 and according to the ICD-10 after 1 January 2008.

\section{Measurement}

Biochemistry was assessed from blood samples collected after overnight fasting during the hospitalisation period. Glycated haemoglobin levels were determined using cation-exchange high-performance liquid chromatography (National Glycohemoglobin Standardization Program certificated; G8, TOSOH, Tokyo, Japan). Lipid levels were determined using enzymatic methods (Advia 1800; Siemens, New York, USA). Creatinine levels were determined using the Jaffé method (Advia 1800; Siemens). Urine protein levels were determined using the dye-binding assay, and urine albumin levels were assessed using the immune-turbidimetric method (Advia 1800; Siemens).

\section{Comparison of cut-off values of daily urinary protein excretion for normoalbuminuria}

Among the 2482 diabetic inpatients who had undergone 24-hour urine collection, only 245 had the data for both urine albumin and protein levels in the same urine sample. The median level of daily protein excretion was $184 \mathrm{mg}$ (IQR $80-620 \mathrm{mg}$ ) and the median level of daily albumin excretion was $58 \mathrm{mg}$ (IQR $15-362 \mathrm{mg}$ ). There was a significant positive correlation between daily urine protein and albumin excretion $(\mathrm{r}=0.884, \mathrm{p}<0.001)$. Receiver operating characteristic (ROC) curves were used to differentiate normal urine albumin excretion $(<30 \mathrm{mg} /$ day $)$, and we found that the area under the curve was 0.956 (95\% CI 0.932 to $0.979 ; \mathrm{p}<0.001$; online supplementary figure). The optimal diagnostic cut-off value for the daily urine protein level was $145 \mathrm{mg}$, which corresponded to a sensitivity of $93.8 \%$ and specificity of $86.5 \%$ for normoalbuminuria. Using $150 \mathrm{mg}$ as diagnostic cut-off value of daily urine protein also gave a sensitivity of $93.8 \%$ and specificity of $86.5 \%$ for normoalbuminuria.

\section{Statistical analysis}

Continuous data are presented as mean $\pm \mathrm{SD}$, whereas categorical data are presented as number (n) with percentage (\%). The linear correlation of daily excretion between 
urine protein and albumin was determined using Spearman's rank correlation coefficient. The ROC curve was used to determine the optimal cut-off value of daily urine protein for normoalbuminuria. One-way analysis of variance (ANOVA) was used to determine the significance of the differences among groups. Pairwise multiple comparisons were conducted to determine the significance of the differences between two groups, if a statistically significant difference was detected via one-way ANOVA; however, Kruskal-Wallis tests were conducted to determine the significance of the differences in the duration of diabetes, triglyceride levels and eGFR values among groups due to the presence of a skewed distribution in these variables. The $\chi^{2}$ test was used to compare categorical variables across groups. The overall significance of univariate survival analysis was determined by the log-rank test using Kaplan-Meier analysis. Cox proportional-hazards regression analyses were conducted to determine the HRs of risk factors. The risk factors in the univariate model were selected based on the findings in table 1 , whereas the risk factors in model 2 were selected based on the statistical significance indicated in the univariate model. Except the inclusion and exclusion criteria, the mean imputation method was used for missing data. A value of $\mathrm{p}<0.05$ was considered statistically significant. Statistical analysis was performed using SPSS V.22.0 (IBM).

\section{RESULTS \\ Comparison of the outcomes between patients with and without fundal examination}

A total of 665 patients with a median diabetes duration of 7 years (IQR 2-12 years) met the criteria for enrolment in the study and were included in these analyses

Table 1 Clinical data of patients according to the presence of CKD and DR

\begin{tabular}{|c|c|c|c|c|c|}
\hline & $\begin{array}{l}\text { CKD(-)DR(-) } \\
(n=306)\end{array}$ & $\begin{array}{l}\text { CKD(-)DR(+) } \\
(n=130)\end{array}$ & $\begin{array}{l}\text { CKD(+)DR(-) } \\
(n=149)\end{array}$ & $\begin{array}{l}\text { CKD(+)DR(+) } \\
(n=80)\end{array}$ & $P$ values \\
\hline Age (years) & $57 \pm 15$ & $62 \pm 13$ & $69 \pm 10$ & $70 \pm 9$ & $<0.001$ \\
\hline Male, n (\%) & $189(61.8 \%)$ & $63(48.5 \%)$ & $82(55.0 \%)$ & $42(52.5 \%)$ & 0.057 \\
\hline BMI $\left(\mathrm{kg} / \mathrm{m}^{2}\right)$ & $23.7 \pm 4.5$ & $23.3 \pm 4.0$ & $24.2 \pm 4.1$ & $24.2 \pm 4.3$ & 0.367 \\
\hline Systolic blood pressure $(\mathrm{mm} \mathrm{Hg})$ & $124 \pm 14$ & $129 \pm 15$ & $127 \pm 15$ & $128 \pm 14$ & 0.004 \\
\hline Diastolic blood pressure (mm Hg) & $74 \pm 11$ & $75 \pm 10$ & $71 \pm 9$ & $72 \pm 10$ & 0.003 \\
\hline Diabetes duration (years) ${ }^{*}$ & $6.7 \pm 6.7$ & $11.4 \pm 7.4$ & $7.9 \pm 7.7$ & $13.2 \pm 8.4$ & $<0.001$ \\
\hline Current smoker, n (\%) & $96(31.4 \%)$ & $36(27.7 \%)$ & $31(20.8 \%)$ & $13(16.3 \%)$ & 0.014 \\
\hline White blood cell count $\left(\times 10^{9} / L\right)$ & $7.8 \pm 5.2$ & $7.2 \pm 2.4$ & $8.3 \pm 3.5$ & $8.4 \pm 3.3$ & 0.227 \\
\hline HbA1c (\%) & $11.5 \pm 2.9$ & $10.6 \pm 2.3$ & $10.4 \pm 3.3$ & $9.3 \pm 2.6$ & $<0.001$ \\
\hline Total cholesterol (mmol/L) & $4.8 \pm 1.3$ & $5.0 \pm 1.3$ & $4.6 \pm 1.3$ & $4.7 \pm 1.5$ & 0.197 \\
\hline Triglyceride $(\mathrm{mmol} / \mathrm{L})^{*}$ & $1.9 \pm 1.9$ & $1.9 \pm 2.2$ & $2.0 \pm 2.2$ & $1.8 \pm 1.3$ & 0.574 \\
\hline HDL cholesterol (mmol/L) & $1.1 \pm 0.4$ & $1.1 \pm 0.4$ & $1.0 \pm 0.3$ & $1.0 \pm 0.4$ & 0.149 \\
\hline eGFR $\left(\mathrm{mL} / \mathrm{min} / 1.73 \mathrm{~m}^{2}\right)^{*}$ & $88 \pm 23$ & $87 \pm 20$ & $45 \pm 13$ & $42 \pm 15$ & $<0.001$ \\
\hline Hypertension, n (\%) & $171(55.9 \%)$ & $93(71.5 \%)$ & $113(75.8 \%)$ & $63(78.8 \%)$ & $<0.001$ \\
\hline Antihypertensive agents, $\mathrm{n}(\%)$ & $91(29.7 \%)$ & $63(48.5 \%)$ & $90(60.4 \%)$ & $47(58.8 \%)$ & $<0.001$ \\
\hline ACE inhibitor or ARB, $n(\%)$ & $58(19.0 \%)$ & $44(33.8 \%)$ & $59(39.6 \%)$ & $32(40.0 \%)$ & $<0.001$ \\
\hline$\alpha$-Blocker, n (\%) & $20(6.5 \%)$ & $14(10.8 \%)$ & $20(13.4 \%)$ & $10(12.5 \%)$ & 0.079 \\
\hline$\beta$-Blocker, n (\%) & $20(6.5 \%)$ & $9(6.9 \%)$ & $3(2.0 \%)$ & $6(7.5 \%)$ & 0.172 \\
\hline Calcium channel blocker, n (\%) & $43(14.1 \%)$ & $28(21.5 \%)$ & $37(24.8 \%)$ & $20(25.0 \%)$ & 0.015 \\
\hline Diuretics, n (\%) & $8(2.6 \%)$ & $6(4.6 \%)$ & $11(7.4 \%)$ & $16(20.0 \%)$ & $<0.001$ \\
\hline Oral antihyperglycaemic drugs, n (\%) & $151(49.3 \%)$ & $65(50.0 \%)$ & $53(35.6 \%)$ & 27 (33.8\%) & 0.005 \\
\hline Insulin secretagogues, n (\%) & $127(41.5 \%)$ & $56(43.1 \%)$ & $46(30.9 \%)$ & $23(28.8 \%)$ & 0.027 \\
\hline Metformin, n (\%) & $95(31.0 \%)$ & $41(31.5 \%)$ & $26(17.4 \%)$ & $17(21.3 \%)$ & 0.007 \\
\hline Thiazolidinediones, n (\%) & $6(2.0 \%)$ & $5(3.8 \%)$ & $2(1.3 \%)$ & $0(0.0 \%)$ & 0.230 \\
\hline$\alpha$-Glucosidase inhibitor, $\mathrm{n}(\%)$ & $10(3.3 \%)$ & $5(3.8 \%)$ & $3(2.0 \%)$ & $2(2.5 \%)$ & 0.811 \\
\hline Insulin therapy, n (\%) & $231(75.5 \%)$ & $80(61.5 \%)$ & $70(47.0 \%)$ & $38(47.5 \%)$ & $<0.001$ \\
\hline Statins, n (\%) & 28 (9.2\%) & $12(9.2 \%)$ & $17(11.4 \%)$ & $12(15.0 \%)$ & 0.442 \\
\hline
\end{tabular}

*Kruskal-Wallis tests to determine the significance of the differences due to skewed distribution in diabetic duration, triglycerides and eGFR. ARB, angiotensin II receptor antagonists; BMI, Body Mass Index; CKD, chronic kidney disease; DR, diabetic retinopathy; eGFR, estimated glomerular filtration rate; $\mathrm{HbA1c}$, glycated haemoglobin; HDL, high-density lipoprotein. 


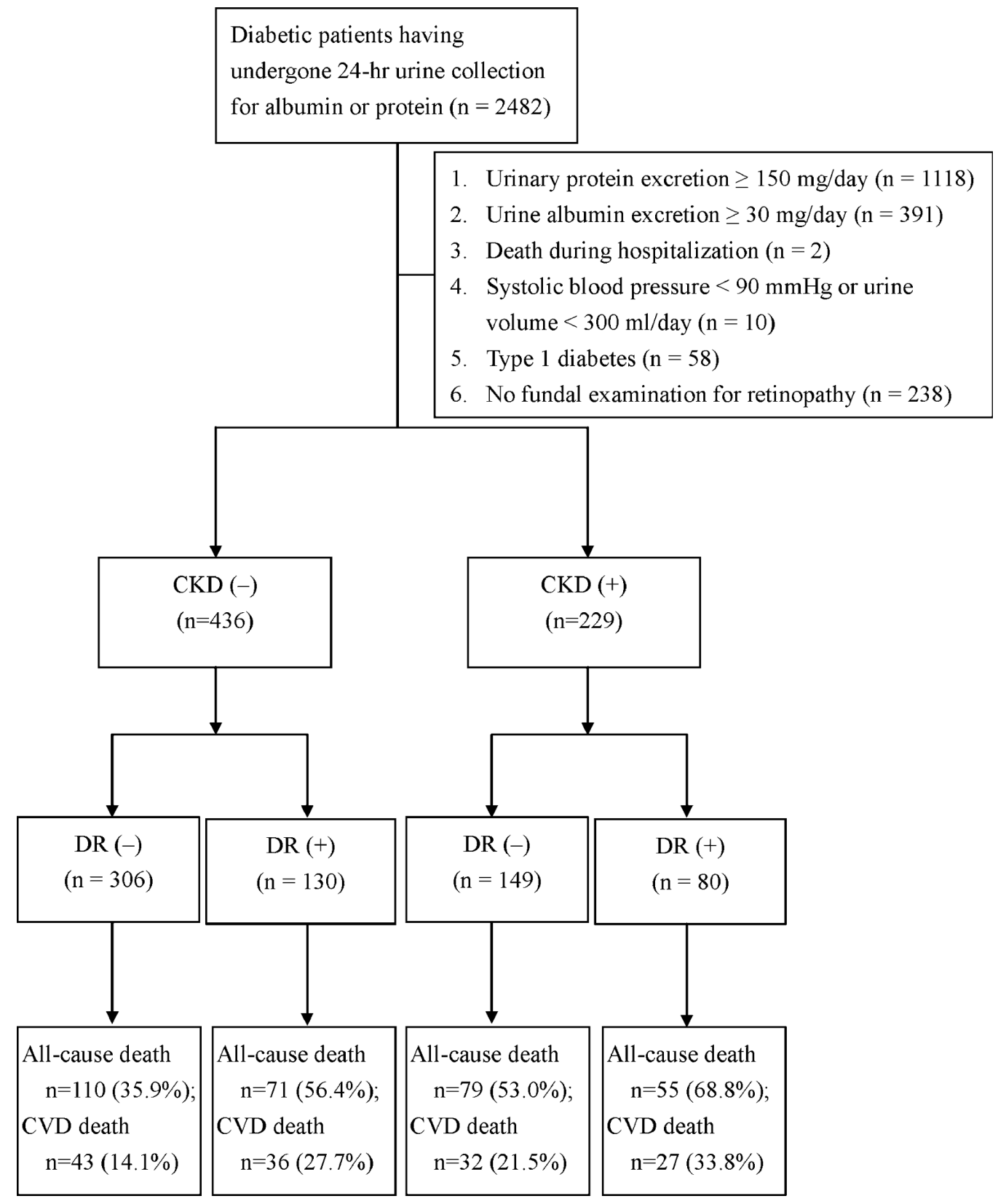

Figure 1 Flow diagram of enrolment of study subjects with normoalbuminuria.

(figure 1). In comparison with the 238 patients who were eligible for all the criteria except for lacking a fundal examination for retinopathy, there were no statically significant differences in age $(62 \pm 14$ vs $63 \pm 15$ years, $\mathrm{p}=0.777)$, gender $(56.5 \%$ men vs $61.3 \%$ men, $\mathrm{p}=0.226)$, diabetes duration $(8.7 \pm 7.7$ vs $8.9 \pm 8.6$ years, $\mathrm{p}=0.789)$, eGFR $\left(73 \pm 29\right.$ vs $\left.71 \pm 30 \mathrm{~mL} / \mathrm{min} / 1.73 \mathrm{~m}^{2}, \quad \mathrm{p}=0.642\right)$, all-cause mortality incidence (6.6 vs 6.5 events/100 person-years, log-rank test $\mathrm{p}=0.888)$ and cardiovascular mortality (2.9 vs 2.9 events/100 person-years, log-rank test $\mathrm{p}=0.965$ ).

\section{Risk of long-term mortality in CKD or DR in patients with} normoalbuminuria

There were 229 (34.4\%) patients with CKD and 210 $(31.6 \%)$ with DR in the 665 enrolled type 2 diabetic inpatients with normoalbuminuria. During a median follow-up of 6.7 years (IQR 4.1-9.6 years), 315 (47.4\%) patients died from any cause; in particular, 138 patients died of cardiovascular disease (figure 1). The all-cause mortality rate was higher in the patients with CKD than in those without CKD (9.4 vs 5.4 events/100 personyears, log-rank test $\mathrm{p}<0.001)$, and the all-cause mortality rate was also higher in the patients with DR than those without DR (9.0 vs 5.6 events/100 person-years, log-rank test $\mathrm{p}<0.001)$. Moreover, the cardiovascular mortality rate was higher in patients with CKD than in those without CKD (4.2 vs 2.4 events/100 person-years, log-rank test $\mathrm{p}<0.001)$; this rate was also higher in patients with DR than in those without DR (4.5 vs 2.2 events/ 100 personyears, log-rank test $\mathrm{p}<0.001)$. 


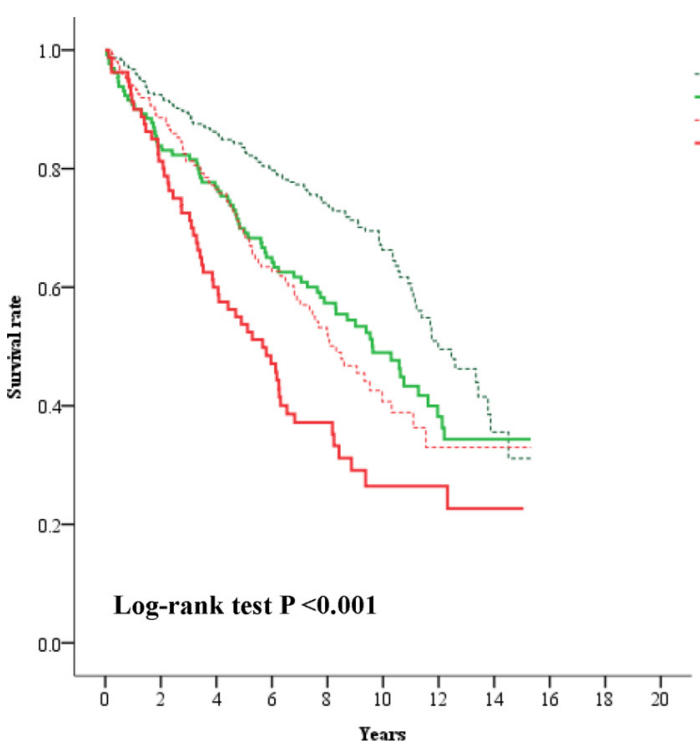

Figure 2 Kaplan-Meier curves showing survival rates categorised according to chronic kidney disease (CKD) and diabetic retinopathy (DR) in type 2 diabetic inpatients with normoalbuminuria.

\section{Combined effect of retinopathy and CKD on long-term mortality}

The proportion of patients with DR was not significantly different between the patients with CKD and those without CKD ( $34.9 \%$ vs $29.8 \%, p=0.207$ ). The 665 patients were separated into four groups based on the presence of CKD and DR, including (1) patients without CKD or DR in the CKD(-)DR(-) group, (2) patients with DR but not CKD in the CKD(-)DR(+) group, (3) patients with CKD but not DR in the CKD (+) DR(-) group and (4) patients with both CKD and DR in the $\operatorname{CKD}(+) \mathrm{DR}(+)$ group. Table 1 shows all the clinical characteristics of patients among these four groups. Figure 2 shows that survival rates were significantly different across these four groups (log-rank test $\mathrm{p}<0.001)$, as demonstrated by KaplanMeier analysis. The highest mortality incidence (12.4 events/100 person-years) was observed in the $\operatorname{CKD}(+)$ $\mathrm{DR}(+)$ group; this value was significantly higher than the 8.1 events $/ 100$ person-years in the $\mathrm{CKD}(+) \mathrm{DR}(-)$ group $(p=0.010)$, the 7.4 events $/ 100$ person-years in the $\mathrm{CKD}(-) \mathrm{DR}(+)$ group $(\mathrm{p}=0.004)$ and the 4.6 events $/ 100$ person-years in the CKD $(-) \mathrm{DR}(-)$ group $(\mathrm{p}<0.001)$. The incidences of mortality in the $\operatorname{CKD}(+) \mathrm{DR}(-)$ and $\mathrm{CKD}(-)$ $\mathrm{DR}(+)$ groups were also significantly higher than that in the $\mathrm{CKD}(-) \mathrm{DR}(-)$ group $(\mathrm{p}<0.001$ and $\mathrm{p}=0.003$, respectively). However, there was no significant difference in the mortality incidence between the $\mathrm{CKD}(+) \mathrm{DR}(-)$ and $\mathrm{CKD}(-) \mathrm{DR}(+)$ groups $(\mathrm{p}=0.479)$.

\section{Cox regression analysis for all-cause and cardiovascular mortality}

To identify the predictive factors for long-term mortality, univariate Cox regression analysis was conducted for all the enrolled patients. In addition to the different groups categorised based on CKD and DR, age, gender, diabetes duration, body mass index (BMI), systolic blood pressure, metformin treatment, insulin treatment and diuretic treatment were significantly associated with total mortality. Using multivariate Cox regression analysis, patients with CKD and DR have the highest HR (2.263; 95\% CI 1.551 to 3.302) for all-cause mortality in comparison with the ones without CKD or DR after adjustment for age, gender, diabetes duration, BMI, systolic blood pressure, metformin treatment, insulin treatment and diuretic treatment (table 2A). Moreover, patients with CKD and DR also had the highest HR (2.471; 95\% CI 1.421 to 4.297) for cardiovascular mortality in comparison with the ones without CKD or DR after adjustment for age, gender, diabetes duration, BMI, systolic blood pressure and ACE inhibitor or angiotensin II receptor antagonist (ARB) treatment (table 2B).

\section{DISCUSSION}

In this retrospective cohort study, we found that patients with NA-CKD have a higher risk of all-cause mortality compared with patients without CKD. Furthermore, the presence of DR imposed a higher mortality risk in patients with NA-CKD.

The mortality risk associated with NA-CKD remains controversial. In the Casale Monferrato study, which had an 11-year follow-up, eGFR showed a significantly inverse trend with long-term mortality only in type 2 diabetic patients with macroalbuminuria, but not in those with microalbuminuria or normoalbuminuria. ${ }^{27}$ Conversely, several studies reported that low eGFR was significantly associated with a higher all-cause mortality risk, independent of albuminuria. ${ }^{28-32}$ The magnitude of the impact on all-cause mortality varied. Rigalleau et $a l^{33}$ reported that NA-CKD was associated with a very low risk of dialysis or mortality in comparison with albuminuric CKD in diabetic patients during a 38-month follow-up study in France. In an Asian study with a 44-month follow-up, albuminuria was associated with a significantly higher risk of renal events, but not cardiovascular events in diabetic patients with CKD. ${ }^{34}$ In the present study, we found that NA-CKD is associated with an approximately 1.8-fold increase in either all-cause mortality or cardiovascular disease, compared with type 2 diabetic patients without CKD. In line with our findings, Hsieh $e t a l^{35}$ reported that eGFR was inversely related to risk of cardiovascular events in type 2 diabetic outpatients with normoalbuminuria during a 4-year follow-up study.

We postulated that heterogeneity in the pathogenesis of NA-CKD might contribute to the differences in results. Different natural courses have been observed in the NA-CKD phenotype: initial albuminuria with regression to normoalbuminuria with intensive renin-angiotensinaldosterone system (RAAS) inhibitor use in some diabetic patients, but eGFR loss might be the only manifestation of renal involvement in others. ${ }^{11} 36$ Based on renal biopsy, tubular-interstitial lesions and arterial hyalinosis were the predominant findings in NA-CKD rather than the typical 
Table 2 Results of Cox regression analysis for the effects of risk factors on (A) all-cause and (B) cardiovascular mortality

\begin{tabular}{|c|c|c|c|c|c|c|c|c|c|}
\hline & \multirow{2}{*}{\multicolumn{3}{|c|}{$\begin{array}{l}\text { Univariate model } \\
\text { Crude }\end{array}$}} & \multicolumn{6}{|c|}{ Multivariate model } \\
\hline & & & & \multicolumn{3}{|c|}{ Model 1} & \multicolumn{3}{|c|}{ Model 2} \\
\hline & HR & $95 \% \mathrm{Cl}$ & $\begin{array}{l}\mathrm{P} \\
\text { values }\end{array}$ & HR & $95 \% \mathrm{Cl}$ & $\begin{array}{l}P \\
\text { values }\end{array}$ & HR & $95 \% \mathrm{Cl}$ & $\begin{array}{l}P \\
\text { values }\end{array}$ \\
\hline \multicolumn{10}{|l|}{ (A) All-cause mortality } \\
\hline $\mathrm{CKD}(-) \mathrm{DR}(-)^{*}$ & 1.000 & & & 1.000 & & & 1.000 & & \\
\hline CKD(-)DR(+) & 1.590 & (1.179 to 2.145$)$ & 0.002 & 1.556 & (1.148 to 2.108$)$ & 0.004 & 1.686 & (1.202 to 2.364$)$ & 0.002 \\
\hline $\mathrm{CKD}(+) \mathrm{DR}(+)$ & 2.791 & (2.016 to 3.866$)$ & $<0.001$ & 2.209 & (1.573 to 3.101$)$ & $<0.001$ & 2.263 & (1.551 to 3.302$)$ & $<0.001$ \\
\hline Age (every 10 years) & 1.455 & (1.318 to 1.607$)$ & $<0.001$ & 1.328 & (1.197 to 1.472$)$ & $<0.001$ & 1.325 & (1.177 to 1.491$)$ & $<0.001$ \\
\hline Gender (male) & 1.763 & (1.394 to 2.229$)$ & $<0.001$ & 1.763 & (1.388 to 2.239$)$ & $<0.001$ & 1.692 & (1.298 to 2.206$)$ & $<0.001$ \\
\hline Current smoker (yes/no) & 1.223 & (0.958 to 1.561$)$ & 0.107 & & & & & & \\
\hline HbA1c (every 1\%) & 0.969 & (0.927 to 1.013$)$ & 0.163 & & & & & & \\
\hline Metformin (yes/no) & 0.776 & (0.604 to 0.998$)$ & 0.049 & & & & 0.751 & (0.549 to 1.028$)$ & 0.074 \\
\hline Insulin secretagogues (yes/no) & 0.851 & (0.677 to 1.070$)$ & 0.167 & & & & & & \\
\hline Insulin therapy (yes/no) & 0.777 & (0.619 to 0.974$)$ & 0.029 & & & & 1.094 & (0.807 to 1.483$)$ & 0.562 \\
\hline Statins (yes/no) & 1.090 & (0.763 to 1.557$)$ & 0.635 & & & & & & \\
\hline ACE inhibitor or ARB (yes/no) & 1.144 & (0.900 to 1.454$)$ & 0.271 & & & & & & \\
\hline $\begin{array}{l}\text { Calcium channel blocker (yes/ } \\
\text { no) }\end{array}$ & 1.237 & (0.942 to 1.625$)$ & 0.125 & & & & & & \\
\hline Diuretics (yes/no) & 2.517 & (1.714 to 3.696$)$ & $<0.001$ & & & & 1.765 & (1.115 to 2.793$)$ & 0.015 \\
\hline Gender (male) & 2.124 & (1.472 to 3.066$)$ & $<0.001$ & 2.132 & (1.465 to 3.102$)$ & $<0.001$ & 2.126 & (1.391 to 3.250$)$ & $<0.001$ \\
\hline Current smoker (yes/no) & 1.326 & (0.922 to 1.908$)$ & 0.128 & & & & & & \\
\hline $\begin{array}{l}\text { Diabetes duration }>7 \text { years } \\
\text { (yes/no) }\end{array}$ & 1.775 & (1.237 to 2.546$)$ & 0.002 & & & & 1.196 & (0.788 to 1.815$)$ & 0.401 \\
\hline BMI (every 1 kg/m²) & 0.885 & (0.843 to 0.928$)$ & $<0.001$ & & & & 0.877 & (0.836 to 0.921$)$ & $<0.001$ \\
\hline Systolic BP (every 10 mm Hg) & 1.157 & (1.034 to 1.295$)$ & 0.011 & & & & 1.035 & (0.912 to 1.175$)$ & 0.593 \\
\hline HbA1c (every 1\%) & 0.977 & (0.914 to 1.045$)$ & 0.503 & & & & & & \\
\hline Metformin (yes/no) & 0.819 & (0.562 to 1.193$)$ & 0.297 & & & & & & \\
\hline Insulin secretagogues (yes/no) & 0.950 & (0.675 to 1.339$)$ & 0.771 & & & & & & \\
\hline Insulin therapy (yes/no) & 0.900 & (0.635 to 1.276$)$ & 0.554 & & & & & & \\
\hline Statins (yes/no) & 0.788 & (0.425 to 1.460$)$ & 0.448 & & & & & & \\
\hline ACE inhibitor or ARB (yes/no) & 1.572 & (1.113 to 2.221$)$ & 0.010 & & & & 1.159 & (0.765 to 1.756$)$ & 0.487 \\
\hline $\begin{array}{l}\text { Calcium channel blocker (yes/ } \\
\text { no) }\end{array}$ & 1.366 & (0.914 to 2.041$)$ & 0.128 & & & & & & \\
\hline Diuretics (yes/no) & 2.387 & (1.316 to 4.330$)$ & 0.004 & & & & 1.321 & (0.618 to 2.821$)$ & 0.473 \\
\hline
\end{tabular}

The risk factors in the univariate model were selected based on the findings in table 1 . The risk factors in model 2 were selected based on the statistical significance indicated in the univariate model.

*The overall $p$ value $<0.001$ among the $\mathrm{CKD}(-) \mathrm{DR}(-), \mathrm{CKD}(-) \mathrm{DR}(+), \mathrm{CKD}(+) \mathrm{DR}(-), \mathrm{CKD}(+) \mathrm{DR}(+)$ groups.

ARB, angiotensin II receptor antagonist; BMI, body mass index; BP, blood pressure; HbA1c, glycated haemoglobin. 
glomerulosclerotic lesions seen with albuminuria in diabetic patients. ${ }^{37}{ }^{38}$ With albuminuria regression due to the widespread use of RAAS inhibitors in recent decades, NA-CKD is being found in majority of DKD patients. The number of patients with normoalbuminuria has been found to be great than those with albuminuria in several large studies of type 2 diabetic patients with CKD. ${ }^{39-41}$ Hence, there is an urgent need to identify the predictors of mortality among this distinct population. ${ }^{42}$

In the present study, patients using ACE inhibitors or ARBs showed a higher risk of cardiovascular mortality in the univariate model, and this finding may result from the higher proportion of CKD patients using these drugs at baseline. In the multivariate model, the use of ACE inhibitors or ARBs at baseline was not significantly associated with cardiovascular mortality. Consistent with these findings, early ARB treatment was not found to significantly improve eGFR in type 2 diabetic patients with urine albumin:creatinine ratio $<300 \mathrm{mg} / \mathrm{g}^{43}$

Although there is a high prevalence of DR in type 2 diabetic patients with albuminuria, ${ }^{19}$ the concordance between DR and CKD was lower in patients with normoalbuminuria than in those with albuminuria. ${ }^{44}$ In the present study, we found that the prevalence of retinopathy was not significantly different between patients with and without CKD. However, the highest risks of all-cause mortality and cardiovascular mortality were shown in the patients with CKD and DR. Compared with the NHANES III population, in which the synergistic effect of CKD and retinopathy on morality was also observed, ${ }^{46}$ our findings showed the evidence in type 2 diabetic inpatients even without albuminuria. Although similar risk factors and cardiovascular effects for DR and CKD have been reported, ${ }^{29} 4748$ the exact mechanism underlying the superimposed DR effect on mortality in type 2 diabetic patients with NA-CKD requires further investigation.

In the present study, both isolated CKD, that is, CKD $(+)$ $\operatorname{DR}(-)$, and isolated DR, that is, $\operatorname{CKD}(-) \operatorname{DR}(+)$, showed significantly higher mortality risks than those with neither CKD nor DR in univariate analyses; however, the significant difference seemed to attenuate in isolated CKD after adjustment for other traditional cardiovascular risk factors. NA-CKD has been reported to be highly associated with cardiovascular risk factors. ${ }^{35} 41$ Therefore, the attenuation of the mortality prediction after adjustment for cardiovascular risk factors might be more obvious in isolated CKD in comparison with isolated DR. Furthermore, it is notable that a higher BMI showed a protective effect for all-cause and cardiovascular mortality in the present study. Although this seems somewhat contradictory to traditional concepts, we were not the only one to report this paradoxical effect of BMI on mortality in patients with diabetes. ${ }^{49}$ Cea Soriano et $a l^{50}$ reported that BMI $\geq 25 \mathrm{~kg} / \mathrm{m}^{2}$ predicted a lower mortality risk than BMI $<25 \mathrm{~kg} / \mathrm{m}^{2}$ in type 2 diabetic patients with CKD.

Among type 2 diabetic patients with normoalbuminuria, high urine albumin excretion $(10-29 \mathrm{mg}$ /day) was reportedly associated with multiple cardiovascular risk factors, as compared with low urine albumin excretion $(<10 \mathrm{mg} /$ day $) .{ }^{51}$ Recently, the highest tertile of the urine albumin excretion rate was found to be associated with diabetic retinopathy and arterial stiffness, in comparison with the lowest tertile among type 2 diabetic patients with normoalbuminuria. ${ }^{52} 53$ In the present study, 257 patients without CKD had available urine albumin data, including 108 patients with low normoalbuminuria $(<10 \mathrm{mg} /$ day) and 149 patients with high normoalbuminuria (10-29 mg/day). However, there was no significant difference in DR prevalence ( $p>0.05)$ or all-cause and cardiovascular mortality (both log-rank test $p>0.05$ ). Further investigations with a large number of cases will be needed to evaluate the association between high normoalbuminuria and mortality.

We acknowledge several limitations in our study. First, we enrolled patients with normoalbuminuria and also normoproteinuria, due to the limited numbers of cases overall. Second, we used the 24-hour urine data instead of spot-urine data since the latter has been well reported in type 2 outpatients previously. ${ }^{54}$ Third, we only included type 2 diabetic inpatients who were admitted to the hospital with a primary diagnosis of poor glucose control. Fourth, we calculated eGFR using the MDRD equation instead of the CKD Epidemiology Collaboration (EPI) equation as consensus had not been reached regarding the use of the CKD-EPI equation in the Taiwanese population. ${ }^{55}$ Finally, we assessed the patients only at baseline, but not during the follow-up. Therefore, treatment might have confounded the results following patients discharged.

In conclusion, DR is a significant predictor for all-cause and cardiovascular mortality in type 2 diabetic inpatients with normoalbuminuria. Presence of DR also showed an impact on mortality for type 2 diabetic inpatients with NA-CKD. Screening for DR and eGFR may help identify those who harbour a high mortality risk after discharge in type 2 diabetic inpatients hospitalised due to poor glucose control, even with normoalbuminuria.

Acknowledgements Mortality data were provided by the Collaboration Center of Health Information Application, Ministry of Health and Welfare, Executive Yuan. The statistical analysis was performed by the Biostatistics Task Force of Taichung Veterans General Hospital, Taichung, Taiwan.

Contributors Y-HL, WH-HS and I-TL contributed to the study design. Y-HL and I-TL participated in the data collection. Y-HL and I-TL participated in the analysis and interpretation of the data. Y-HL drafted the manuscript. I-TL had full access to the study data. I-TL is the guarantor. All the authors performed a critical revision of the manuscript for important intellectual content.

Funding This work was supported by Taichung Veterans General Hospital, Taichung, Taiwan (grant no. TCVGH-TCVGH-1063501E, TCVGH-1063502C), and the Ministry of Science and Technology, Taiwan (grant no. MOST 105-2314-B-075A-003).

Disclaimer The funders had no role in the decision to submit the manuscript for publication.

Competing interests None declared.

Patient consent Not required.

Ethics approval The research protocol was approved by the Institutional Review Board of Taichung Veterans General Hospital. 
Provenance and peer review Not commissioned; externally peer reviewed.

Data sharing statement № additional data are available.

Open access This is an open access article distributed in accordance with the Creative Commons Attribution Non Commercial (CC BY-NC 4.0) license, which permits others to distribute, remix, adapt, build upon this work non-commercially, and license their derivative works on different terms, provided the original work is properly cited, appropriate credit is given, any changes made indicated, and the use is non-commercial. See: http://creativecommons.org/licenses/by-nc/4.0/.

\section{REFERENCES}

1. Collins AJ, Foley RN, Chavers B, et al. United States renal data system 2011 annual data report: atlas of chronic kidney disease \& end-stage renal disease in the United States. Am J Kidney Dis 2012;59:A7, e1-420.

2. Hwang SJ, Tsai JC, Chen HC. Epidemiology, impact and preventive care of chronic kidney disease in Taiwan. Nephrology 2010;15(Suppl 2):3-9.

3. Crawford TN, Alfaro DV, Kerrison JB, et al. Diabetic retinopathy and angiogenesis. Curr Diabetes Rev 2009;5:8-13.

4. Maffi P, Secchi A. The burden of diabetes: emerging data. Dev Ophthalmol 2017;60:1-5.

5. Klein BE. Overview of epidemiologic studies of diabetic retinopathy. Ophthalmic Epidemiol 2007;14:179-83.

6. Porrini E, Ruggenenti P, Mogensen CE, et al. Non-proteinuric pathways in loss of renal function in patients with type 2 diabetes. Lancet Diabetes Endocrinol 2015;3:382-91.

7. American Diabetes Association. 10. Microvascular complications and foot care. Diabetes Care 2017;40:S88-S98.

8. Lee IT, Sheu WH, Lin SY. The impact of creatinine clearance rate, daily urinary albumin, and their joint effect on predicting death in diabetic inpatients after discharge: an observational study. Medicine 2016;95:e2804.

9. Afkarian M, Zelnick LR, Hall YN, et al. Clinical manifestations of kidney disease among US adults with diabetes, 1988-2014. JAMA 2016;316:602-10.

10. Kramer HJ, Nguyen QD, Curhan G, et al. Renal insufficiency in the absence of albuminuria and retinopathy among adults with type 2 diabetes mellitus. JAMA 2003;289:3273-7.

11. Pugliese G. Updating the natural history of diabetic nephropathy. Acta Diabetol 2014;51:905-15.

12. Willard AL, Herman IM. Vascular complications and diabetes: current therapies and future challenges. J Ophthalmol 2012;2012:1-14.

13. Eshaq RS, Aldalati AMZ, Alexander JS, et al. Diabetic retinopathy: breaking the barrier. Pathophysiology 2017;24:229-41.

14. Cheung N, Wang JJ, Klein R, et al. Diabetic retinopathy and the risk of coronary heart disease: the Atherosclerosis Risk in Communities Study. Diabetes Care 2007;30:1742-6.

15. Xie J, Ikram MK, Cotch MF, et al. Association of diabetic macular edema and proliferative diabetic retinopathy with cardiovascular disease: a systematic review and meta-analysis. JAMA Ophthalmol 2017;135:586-93.

16. Alonso N, Traveset A, Rubinat E, et al. Type 2 diabetes-associated carotid plaque burden is increased in patients with retinopathy compared to those without retinopathy. Cardiovasc Diabetol 2015;14:33.

17. Ellis TP, Choudhury RH, Kaul K, et al. Diabetic retinopathy and atherosclerosis: is there a link? Curr Diabetes Rev 2013;9:146-60.

18. Kramer CK, Rodrigues TC, Canani LH, et al. Diabetic retinopathy predicts all-cause mortality and cardiovascular events in both type 1 and 2 diabetes: meta-analysis of observational studies. Diabetes Care 2011;34:1238-44.

19. Hsieh YM, Lee WJ, Sheu WH, et al. Inpatient screening for albuminuria and retinopathy to predict long-term mortality in type 2 diabetic patients: a retrospective cohort study. Diabetol Metab Syndr 2017;9:29

20. Torffvit O, Lövestam-Adrian M, Agardh E, et al. Nephropathy, but not retinopathy, is associated with the development of heart disease in type 1 diabetes: a 12-year observation study of 462 patients. Diabet Med 2005;22:723-9.

21. van Hecke MV, Dekker JM, Stehouwer CD, et al. Diabetic retinopathy is associated with mortality and cardiovascular disease incidence: the EURODIAB prospective complications study. Diabetes Care 2005;28:1383-9.

22. Parving $\mathrm{HH}$, Mogensen $\mathrm{CE}$, Thomas $\mathrm{MC}$, et al. Poor prognosis in proteinuric type 2 diabetic patients with retinopathy: insights from the RENAAL study. QJM 2005;98:119-26.
23. Webster AC, Nagler EV, Morton RL, et al. Chronic kidney disease. Lancet 2017;389:1238-52

24. Inker LA, Astor BC, Fox CH, et al. KDOQI US commentary on the $2012 \mathrm{KDIGO}$ clinical practice guideline for the evaluation and management of CKD. Am J Kidney Dis 2014;63:713-35.

25. American Diabetes Association. Standards of medical care in diabetes-2014. Diabetes Care 2014;37(Suppl 1):S14-80.

26. Wilkinson CP, Ferris FL, Klein RE, et al. Proposed international clinical diabetic retinopathy and diabetic macular edema disease severity scales. Ophthalmology 2003;110:1677-82.

27. Bruno G, Merletti F, Bargero G, et al. Estimated glomerular filtration rate, albuminuria and mortality in type 2 diabetes: the Casale Monferrato study. Diabetologia 2007;50:941-8.

28. So WY, Kong AP, Ma RC, et al. Glomerular filtration rate, cardiorenal end points, and all-cause mortality in type 2 diabetic patients. Diabetes Care 2006;29:2046-52.

29. Wada T, Haneda M, Furuichi K, et al. Clinical impact of albuminuria and glomerular filtration rate on renal and cardiovascular events, and all-cause mortality in Japanese patients with type 2 diabetes. Clin Exp Nephrol 2014;18:613-20.

30. Pálsson R, Patel UD. Cardiovascular complications of diabetic kidney disease. Adv Chronic Kidney Dis 2014;21:273-80.

31. Toyama T, Furuichi K, Ninomiya T, et al. The impacts of albuminuria and low eGFR on the risk of cardiovascular death, all-cause mortality, and renal events in diabetic patients: meta-analysis. PLoS One 2013;8:e71810.

32. Svensson MK, Cederholm J, Eliasson B, et al. Albuminuria and renal function as predictors of cardiovascular events and mortality in a general population of patients with type 2 diabetes: a nationwide observational study from the Swedish National Diabetes Register Diab Vasc Dis Res 2013;10:520-9.

33. Rigalleau V, Lasseur C, Raffaitin C, et al. Normoalbuminuric renalinsufficient diabetic patients: a lower-risk group. Diabetes Care 2007;30:2034-9.

34. Lee E, Oh HJ, Park JT, et al. The incidence of cardiovascular events is comparable between normoalbuminuric and albuminuric diabetic patients with chronic kidney disease. Medicine 2016;95:e3175.

35. Hsieh YT, Kuo JF, Su SL, et al. Subnormal estimated glomerular filtration rate strongly predict incident cardiovascular events in type 2 diabetic Chinese population with normoalbuminuria. Medicine 2016;95:e2200.

36. Katayama S, Moriya T, Tanaka S, et al. Low transition rate from normo- and low microalbuminuria to proteinuria in Japanese type 2 diabetic individuals: the Japan Diabetes Complications Study (JDCS). Diabetologia 2011;54:1025-31.

37. Ekinci El, Jerums G, Skene A, et al. Renal structure in normoalbuminuric and albuminuric patients with type 2 diabetes and impaired renal function. Diabetes Care 2013;36:3620-6.

38. Shimizu M, Furuichi K, Yokoyama H, et al. Kidney lesions in diabetic patients with normoalbuminuric renal insufficiency. Clin Exp Nephrol 2014;18:305-12.

39. Thomas MC, Macisaac RJ, Jerums G, et al. Nonalbuminuric renal impairment in type 2 diabetic patients and in the general population (national evaluation of the frequency of renal impairment cO-existing with NIDDM [NEFRON] 11). Diabetes Care 2009;32:1497-502.

40. Penno G, Solini A, Bonora E, et al. Clinical significance of nonalbuminuric renal impairment in type 2 diabetes. $J$ Hypertens 2011;29:1802-9.

41. Yokoyama $\mathrm{H}$, Sone $\mathrm{H}$, Oishi $\mathrm{M}$, et al. Prevalence of albuminuria and renal insufficiency and associated clinical factors in type 2 diabetes: the Japan Diabetes Clinical Data Management study (JDDM15). Nephrol Dial Transplant 2009;24:1212-9.

42. Pugliese G, Solini A, Bonora E, et al. Chronic kidney disease in type 2 diabetes: lessons from the renal insufficiency and cardiovascular events (RIACE) Italian Multicentre Study. Nutr Metab Cardiovasc Dis 2014;24:815-22.

43. Tanamas SK, Saulnier PJ, Fufaa GD, et al. Long-term effect of losartan on kidney disease in American Indians with type 2 diabetes: a follow-up analysis of a randomized clinical trial. Diabetes Care 2016;39:2004-10.

44. Penno G, Solini A, Zoppini G, et al. Rate and determinants of association between advanced retinopathy and chronic kidney disease in patients with type 2 diabetes: the Renal Insufficiency And Cardiovascular Events (RIACE) Italian multicenter study. Diabetes Care 2012;35:2317-23.

45. Rodríguez-Poncelas A, Mundet-Tudurí X, Miravet-Jiménez S, et al. Chronic kidney disease and diabetic retinopathy in patients with type 2 diabetes. PLoS One 2016;11:e0149448.

46. Ricardo AC, Grunwald JE, Parvathaneni S, et al. Retinopathy and CKD as predictors of all-cause and cardiovascular mortality: National 
Health and Nutrition Examination Survey (NHANES) 1988-1994. Am $J$ Kidney Dis 2014;64:198-203.

47. Grunwald JE, Pistilli M, Ying GS, et al. Retinopathy and the risk of cardiovascular disease in patients with chronic kidney disease (from the Chronic Renal Insufficiency Cohort study). Am J Cardiol 2015;116:1527-33.

48. Semeraro F, Cancarini A, dell'Omo R, et al. Diabetic retinopathy: vascular and inflammatory disease. J Diabetes Res 2015;2015:1-16.

49. Chang HW, Li YH, Hsieh $\mathrm{CH}$, et al. Association of body mass index with all-cause mortality in patients with diabetes: a systemic review and meta-analysis. Cardiovasc Diagn Ther 2016;6:109-19.

50. Cea Soriano L, Johansson S, Stefansson B, et al. Cardiovascular events and all-cause mortality in a cohort of 57,946 patients with type 2 diabetes: associations with renal function and cardiovascular risk factors. Cardiovasc Diabetol 2015;14:38

51. Pugliese G, Solini A, Fondelli C, et al. Reproducibility of albuminuria in type 2 diabetic subjects. Findings from the Renal Insufficiency
And Cardiovascular Events (RIACE) study. Nephrol Dial Transplant 2011;26:3950-4.

52. Karoli R, Fatima J, Shukla V, et al. Predictors of diabetic retinopathy in patients with type 2 diabetes who have normoalbuminuria. Ann Med Health Sci Res 2013;3:536-40.

53. Yoon HE, Kim ES, Mo EY, et al. High normal albuminuria is associated with arterial stiffness and carotid atherosclerosis in Korean patients with type 2 diabetes. Nutr Metab Cardiovasc Dis 2015;25:787-94.

54. Salinero-Fort MÁ, San Andrés-Rebollo FJ, de Burgos-Lunar C, et al. Cardiovascular and all-cause mortality in patients with type 2 diabetes mellitus in the MADIABETES cohort study: association with chronic kidney disease. $J$ Diabetes Complications 2016;30:227-36.

55. Chen LI, Guh JY, Wu KD, et al. Modification of diet in renal disease (MDRD) study and CKD epidemiology collaboration (CKD-EPI) equations for Taiwanese adults. PLoS One 2014;9:e99645. 